\title{
Using the eye of the camera to bare racism: A photovoice project
}

Bharati Sethi Kings University College, Western University, Canada

\begin{abstract}
INTRODUCTION: Researchers have well established that visible minorities experience discrimination in the labour market and racism at work; however, few studies have explored the experiences of immigrant visible minority women, especially those residing outside of large urban areas. The focus of this article is to explore participants' experiences of discrimination and racism using photovoice methodology.

METHODS: This Canadian study used an arts-based qualitative method in the form of a modified photovoice where 17 participants took photographs of their work and health experiences and discussed the meaning of their photographs and narratives in the interviews.

FINDINGS: Results indicate that participants experienced discrimination in the labour market, and racism at work. In the absence of language, participants found the eye of the camera as an effective methodological tool to uncover and communicate their lived experiences of discrimination and racism.
\end{abstract}

CONCLUSIONS: Social workers can utilise photovoice for exploring sensitive issues such as experiences of discrimination and racism in a safe context with marginalised populations. They can use the participant-generated photographic images as an education and advocacy tool to prevent discrimination and racism in their communities.

KEYWORDS: photovoice, racism, discrimination, immigrant women, arts-based qualitative method

A growing constituent of Canada's rich multicultural mosaic, now accounts for 5.1 million individuals (Chui \& Maheux, 2011). Women comprise $51 \%$ (or 2.6 million) of the total visible minority population in Canada. Visible minorities are defined under the Employment Equity Act as "persons, other than Aboriginal peoples, who are non-Caucasian in race or non-white in colour" (Chui \& Maheux, 2011, p. 38). Globally, changes in immigration policies, globalisation, war, natural disasters and other economic and non-economic reasons have led to migration of individuals and families from Third World to First World nations. This migration has produced dramatic changes in the composition of ethnic minority populations in Canada and Aotearoa New Zealand. As a result, marginalisation of minority ethnic communities has become an important and sensitive topic in these countries (Chile, 2002). It can then be expected that globally social workers will encounter visible minority populations in their case load and must have an awareness of discrimination this population encounters post-migration to assist migrants in their settlement.

The focus of this article is to understand the participants' experiences of discrimination and racism using photovoice methodology. The study seeks to contribute to existing literature on immigrant women's postmigratory experiences and on the use of photovoice. This research is unique, in which
AOTEAROA

NEW ZEALAND SOCIAL WORK 28(4), 17-28.

CORRESPONDENCE TO: Bharati Sethi

bsethi3@uwo.ca 
it modified the photovoice methodology to effectively engage participants in a meaningful one-on-one conversation with the researcher. This article is based on the author's doctoral thesis (Sethi, 2014).

This article is organised in the following sections: first, a review of literature is provided on discrimination and racism of visible minority populations and on photovoice. This is followed by an account of the study background, research method, findings and discussion of the implications. Finally, a conclusion is offered.

\section{Literature review}

\section{Discrimination and racism of visible minority populations}

Research indicates that visible minority women are more likely to experience discrimination (direct and systemic) (Sethi \& Williams, 2015) and racism (Sethi \& Williams, 2015; Turrittin, Hagey, Guruge, Collins, \& Mitchell, 2002) than non-visible minority women. Direct discrimination involves an intentional behaviour to treat individual(s) unfavourably or in a negative manner based on attributes such as race, class, sex, age, gender, ability, sexual orientation, religion, immigrant or marital status. Treating someone badly or harming them based on their group membership (such as identifying as Muslim) is an example of direct discrimination. In systemic discrimination, an organisation's practices, policies and procedures disadvantage certain individuals due to personal attributes such as race, class, age, gender or sexual orientation (Johnson, 2006). Although direct discrimination is blatant, systemic discrimination is invisible and often hard to identify (Johnson, 2006).

Reitz (2001, p. 253) explains that employment discrimination refers to a "negative employment decision based on status such as a birthplace or origins, rather than based solely on credentials and qualifications directly related to the potential productivity of the employee." Even though many visible minority immigrants are highly qualified, they are more likely to work in low-skilled jobs and often earn less than the Canadianborn workers (Johnson, 2006). Such discrimination is systemic and less visible (Hyman, 2009). Systemic discrimination appears to be a major barrier preventing visible minority women from economic and social integration (Mahtani, 2004). On the discourse of race, Caragata (1999) powerfully articulates:

While non-British, European immigrants also brought differences in language and culture they were not as likely to seem so 'foreign' and therefore threatening in part because they were less 'visible'. This may suggest that our willingness to accommodate a multicultural public is affected by the degree of noticeable difference, with race as a longstanding and obvious such marker (p. 273).

Racism penetrates larger structures of society such as health, employment, immigration, legal and education systems, as well as institutional policies locally, nationally and internationally. Photovoice, an imagebased methodology, offers a flexible method to explore and address the issues of discrimination and racism in a safe context with culturally diverse and marginalised populations. Photovoice has the potential to empower the marginalised and vulnerable populations by giving them voice and visibility (Wang, 1999; Wang \& Burris, 1994).

\section{Photovoice}

Photovoice methodology was first introduced by Caroline Wang (1999) in her research with village women in rural China, inspired by noted Brazilian educator Paulo Freire's (2005) approach to critical education (Wang \& Redwood-Jones, 2001, p. 561). Using feminist theorising and documentary photography, photovoice attempts to bring "new or seldom-heard ideas, images, conversations and voices into the public 
forum" through a dialogic process between the participants and the researchers (Wang \& Redwood-Jones, 2001, p. 561). Paulo Freire (2005) argued that it is through the process of interpretation of the images (photos that he provided) that participants recognised their reality, raising their critical consciousness and thus, as informed subjects they participated in their own freedom from oppression (Gordon, 2005; Singhal \& Devi, 2003). There are three main goals of photovoice: "To enable people (a) to record and reflect their community's strengths and concerns, (b) to promote critical dialogue and knowledge about personal and community issues through largeand small-group discussion of their photographs and (c) to reach policy makers" (Wang, 1999, p. 185).

Although extensive literature exists where researchers have used photovoice for diverse projects and with diverse populations, a review of literature suggests that this methodology is underutilised in social work research. The lack of social work research using photovoice methodology "may reflect a lack of knowledge and use of the method that results in missed opportunities to develop emic-based, action-oriented research" (Lal, Jarus, \& Suto, 2012, p. 186), which can directly affect the lives of marginalised populations and communities. This vivid image-based methodology is suitable for social work research, as it seems to have a proven ability to generate new knowledge for marginalised populations who have little opportunity to share, interpret and voice their lived experiences in a creative and nuanced way (Sutherland \& Cheng, 2009).

\section{Study background}

This article is part of a larger doctoral study conducted in Canada, which explored the work and health experiences of immigrant/ refugee visible minority women (see Sethi, 2014 for study overview). This research built on the author's Master of Social Work (MSW) thesis that examined the strengths and barriers to newcomer integration in the following five areas: education, employment, health, social support and training (Sethi, 2009). With an increasing number of immigrant/refugee women from the visible minority population moving from large urban centres such as Toronto, Montreal and Vancouver to this middle-sized urban-rural region, members of a local newcomer task force, called the Immigrant, Settlement, Training, Employment and Partnership (ISTEP), felt that it was important to understand the women's post-migratory experiences to foster their economic and social integrations. ISTEP members include representatives from the local healthcare agencies, social services, employment sector, government organisations, immigrants and refugees. The author agreed to develop the earlier MSW study and conduct this current research in collaboration with ISTEP. The members of the task force included health practitioners, social workers, employers, policy makers, immigrants and refugees. The task force acted as community advisory members throughout the research project and also helped in finance part of the project. This article reports only the findings related to participants' experiences of racism and discrimination from the larger study.

\section{Research methodology}

\section{Design}

This research utilised arts-based inquiry in the form of modified photovoice to dig deep through the superficial layers of women's lived experiences and to uncover the nuances and the hidden meanings of their employment and health experiences. The author modified photovoice methodology to collect the research data. In a typical photovoice project, participants meet in groups to share, discuss and analyse the participant-generated photographs. In the current research, participants were interviewed individually. Although the author recognises the importance of group dialogue in identifying community issues, 
the photovoice method was modified to make this project more accessible to the participants. Often, individuals whose stories researchers most want to hear are not accessible. For example, participants in this photovoice study were working two to three jobs. If the data were collected using a group format, it would have been difficult to access most of the study participants who participated in the photovoice project.

One focus group was conducted as a form of member checking (Padgett, 2008) with the participants so that they could "confirm or disconfirm the accuracy of the research observations and interpretations" (Rubin \& Babbie, 2005, p. 464). Prior to the focus group, transcripts from the individual interviews were emailed to the participants so that they could check for any discrepancy and confirm if the interviews had been transcribed accurately. During the focus group session, the key themes of the study were summarised and presented to the participants along with the author's interpretations and conclusions of the themes. She asked participants to collectively reflect on the photographs and to indicate if they agreed or disagreed with the findings. Although this process was time-consuming, it strengthened the accuracy of the findings and provided a trustworthy account of the women's stories.

\section{Ethical considerations}

Ethical approval for this research was given by Wilfrid Laurier University Research Ethics Board, Ontario, Canada. In addition to university ethical approval, I engaged the participants as equal partners in the research process, making deliberate efforts to ensure that the stages of the research process were transparent to the participants and clarifying any deviation in the research process. Further, in my efforts to maximise the participants' sense of control over issues related to them, I asked the women to choose their pseudonym. In terms of confidentiality, I was mindful that my research included participants from rural areas where, due to their minority status, they may be easily identified and thus subject to the unintended harm based on their ethnic, religious or immigrant status (for example, being stereotyped or experiencing racism). In reporting research findings, I was extremely careful that I did not divulge any identifying information about a person's place of work or location. In my efforts to minimise the risk to the participants, I also re-visited the issue of voluntary participation in the study several times during the long period of data collection.

\section{Data collection and analysis}

This study used maximum variation purposive sampling to recruit visible minority participants $(\mathrm{N}=17)$, characterised as immigrants or refugees from diverse backgrounds (educational, socio-economic and religious). Participants were provided with digital cameras. They were asked to take photographs of their work and health experiences. Women were then interviewed individually regarding their photographs.

To locate the nuances of women's selfgenerated photographic images, interview questions were designed around the following themes: (a) Choice - Why did you choose this particular photo? (b) Theme Tell me about the person, place, object, or colours, in the photograph, (c) Relationship - How does the photograph relate to you, your family, community, nation, work and health? (d) Issues - What are the individual and societal issues your photograph addresses? and (e) Message - What message do you want to give employers, healthcare practitioners and policy makers through these images?

Interviews were analysed using Charmaz's (2006) constructivist grounded theory to develop initial codes, focussed codes and preliminary themes. Intersectionality analysis (Bilge, 2009) guided the development of the final analytical themes. Data were coded using qualitative software NVivo (QSR International). 


\section{Sample}

Seventeen women participated in the photovoice project. They emigrated to Canada from East Asia, South-Asia, Africa, Latin America, and the Caribbean. Participants spoke varied languages as their mother tongue - Mandarin, Cantonese, Showna, Spanish, Punjabi, Hindi, Tamil, Tagolog and Chavacano (a Spanish-based creole language spoken in the Philippines). The median age was between 35 and 44 years.

Below are the two main themes of the study, namely (a) discrimination in the labour market and $(b)$ racism based on data collected from 17 participants are reported. These themes are summarised from the women's photographs and narratives around notions of choice, theme, relationship, issues and message.

\section{Findings}

The image that precedes this section illustrates vividly the illumination of experience offered by photovoice. The photographer Marcella writes about Figure 1:

This picture represents what I felt when I moved to Canada. I was feeling different in many ways, because of the language, culture and physical attributes. I did not know until then that I was a visible minority. (Marcella, research participant)

\section{Discrimination in the labour market}

This theme represents the participants' experiences of discrimination in the labour market. Even though the women did not know each other, they took similar photographs of trees with branches cut (Figure 2), a dead tree, trees with no leaves and trees that were undernourished and dying to show how labour market discrimination affected them. This theme was further sub-divided into non-recognition of human and social capital and feeling caged.

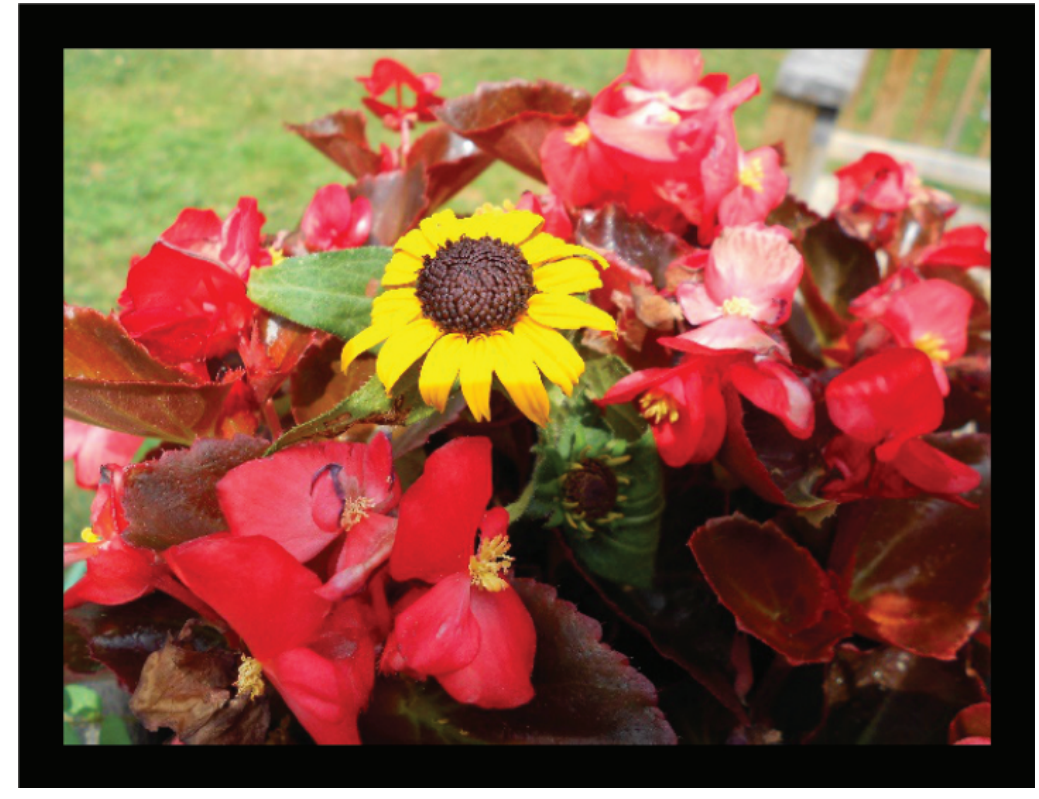

Figure 1:Yellow flower among red flowers

\section{Non-recognition of human and social capital}

Women's human and social capital obtained in their home country was not recognised in Canada. Through her photograph, (Figure 2) Chinja (from Africa) states, "By not recognising my education and skills they have cut my branches...I am depressed I cannot go further".

Other women shared that as their human and social capital obtained in their home country was not recognised they could not find paid employment in Canada. Marcella stated: "I cannot find work." Enigma from the Philippines shared Marcella's experiences of discrimination in the labour market. Even though she had a Master's degree, on migrating to Canada she could not even find volunteering work in her field of choice. Pointing to her photograph of a "dark cloud" she stated: "As an immigrant there were many dark days and uncertainty. I did not know if the decision I made was the correct one - to come to Canada. I wasn't sure if I would live my potential". 


\section{QUALITATIVE RESEARCH}

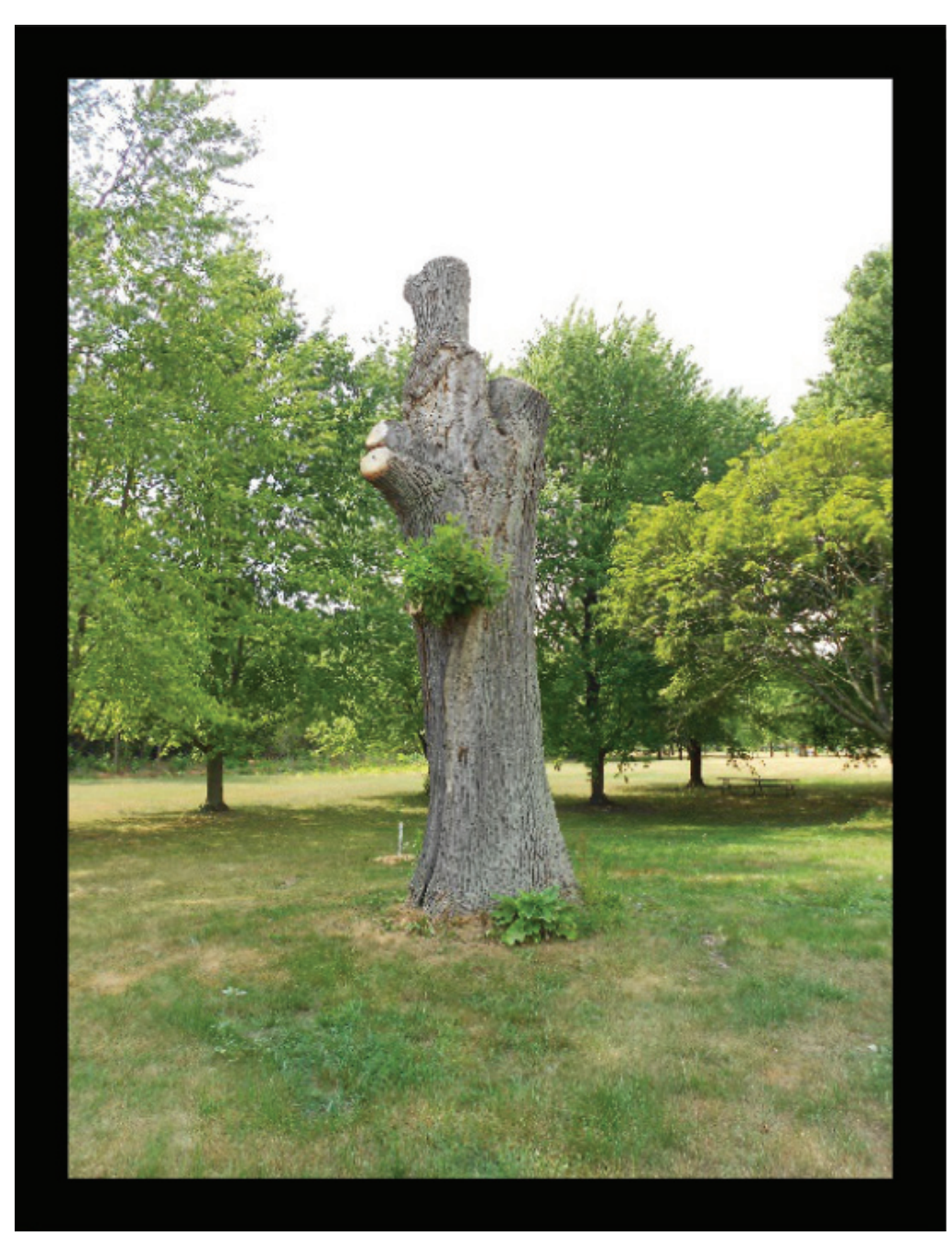

Figure 2: Tree with branches cut (taken by Chinja)

Susan, who had a PhD from China, also doubts her decision to come to Canada. She had a good job and high social status premigration. Post migration, she could only find work as a server in a local food court as her PhD from China was not recognised in Canada. She sighs, "No one would open the door. No one would give me the desired position as I am a visible minority immigrant". Her photo of a dying shrub is accompanied by the following narrative: "As time passes by in Canada and you cannot find a job, the hopes that I came here with start dropping...". Rudo, an executive assistant from Africa was university educated and worked as an executive assistant in her country. The only job she could find post-migration was catching chickens as she lacked Canadian experience in her field and her prior education and experience was completely invalidated in Canada. As a result of invalidating the women's human and social capital gained in their home country, the participants were forced into jobs that did not match up their education and skills. One participant expressed the feeling like a bird, who was caged and could not fly to her dreams. Other participants expressed the feeling caged in other ways.

\section{Feeling caged}

Even after retraining and obtaining a human resources diploma from Canada, Janavi (from India) found that nobody would hire her in a human resources position due to her social location of immigrant and visible minority. Due to discrimination, she could not live her potential and felt caged in a minimum wage job:

\section{I feel caged. I am always locked. I am} the outsider. I am still the outsider-the OTHER. I almost feel as if I don't have the right to be here...I have so much potential; however, the barriers in front of me do not allow me to pursue the career I want or to live my full potential (Janavi).

Ding, an engineer from the Philippines, also feels "caged" as she cleaned offices for a living and could not find employment in her field. She stated:

This picture of birds in a cage represents desire for freedom. Because I am an immigrant I am not free to do what I like to do as far as employment is considered. Because I am an immigrant, my Canadian experience and my education from the Philippines is not recognised here. Also my accent becomes a barrier to finding a job (Ding).

Durga's teaching license from India was not recognised in Canada and she worked in a 
contract administrative position at a local school. She took a photo of a clock to state that her time doing work that she does not enjoy passes very slowly. Similar to Janavi and Ding, she feels caged at her workplace. She adds: "Sometimes I feel like...I feel that these people had this feeling that I ... because I am South-Asian immigrant that I couldn't accomplish much". Similar to Durga, Sherman, an aesthetician from Jamaica, is not happy with her work as a server in a seniors' residence. But she cannot find another job to match her potential. Krishna continues to struggle after 18 years. She feels like a bird in a cage that has not been able to secure her wings to fly to her dreams as her education and experience go unrecognised in Canada. She is unable to find work that she would enjoy. Similar to Durga, she took a photo of a clock: "I feel like after 18 years of struggling in Canada I still haven't integrated. I haven't moved forward. I am still surviving. I would like to move beyond the survival mode". Aishwarya empathises with other participants. She came from a wealthy family in India. After joining her husband in Canada, she worked with him in a pizza store until she was able to obtain a financial analyst license and start her own business. Until then, she felt she was stuck in a cage through which she could only view her dreams but was not sure how to reach them. Alma does not have the means to start a business in Canada. She had a successful pastry business in Mexico. She is familiar with the barriers to employment and how they can cage a person in a survival job. Wherever she goes, she is asked if she has Canadian work experience. Her photo of a branch fallen down and obstructing her way demonstrates her experiences:

There are many barriers language, not having my Mexico experiences recognised, not having Canadian experience, which is impossible to get when you are new here. (Alma)

Along with experiencing language barriers, deskilling and discrimination in the labour market, participant's narratives also highlight experiences of racism.

\section{Racism}

This theme represents some of the participants' experiences of racism. It is divided into two sub-themes: racism at work and response to racism

\section{Racism at work}

Several women in the research were working as personal support workers (Rudo, Chinja, Ruvashe and Harmony). They each experienced racism at work from co-workers and residents of the retirement/nursing home. Rudo took the above photo (Figure 3) of a washing machine to describe her experiences of racism at work:

The washing machine is full of dirty things inside. People look at us as if we are dirty... When we see "blackness" they relate it to dirt. Like the lady at work (manager) said, "No matter how many times you wash your hands you won't be able to clean yourself" (Rudo).

She feels distressed at being called a "nigger" at work and some of the residents do not want her to touch them with her black skin when she is trying to assist them with their personal care.

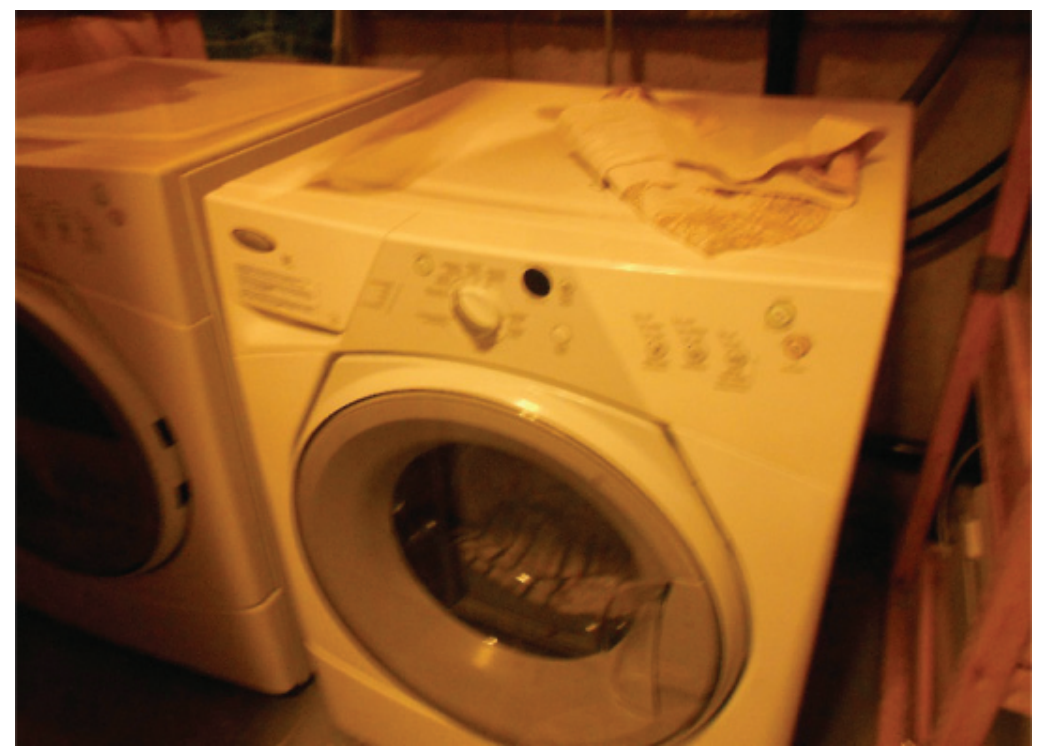

Figure 3: Washing Machine(taken by Rudo) 
Chinja took a photo of an "odd looking tree" and she described her experiences of racism at work:

This is all typical of women of colour in our workplace. We are the odd ones out. Clients and workers make sure we feel and know that we are the odd ones out. Comments are passed about our skin colour, our accent, our hair. We greet our fellow white-coloured worker and they don't respond to our greetings. They just keep quiet... (Chinja)

Ruvashere called her interactions with a senior resident in the retirement home where she was employed:

The lady had a bowel movement, and she was covered in this bowel movement everywhere-the bed, the walls, her hands, her hair, everywhere. And I went in and I said " $\mathrm{Hi}$, I am going to help you clean up", and she was like, "Do not touch me with your black hands" (Ruvashe).

Harmony points to her photo of flowers depicting "oneness" and noted..."It's like at work we have war, with our workmates. It doesn't need to be war; we can do it like together like this...black or white". Ding noticed that the children that she worked with in her second job would ask for help from the white staff rather than her. Janavi also feels "invisible" at her place of work: "Well, as a call centre representative I was non-existent. They gave me a corner and left me alone".

Sherman is also familiar with experiencing racism from a co-worker. She feels that while the management is aware of the problem they will not do anything. Being a newcomer, she is not aware of the policies around complaints and fears losing her job. Her photo of a rock is accompanied by the following narrative: "This rock represents how hard employers' hearts can be; no consideration for their employees, no remorse. They harden their hearts and it's all about the job".

\section{Response to racism}

Rudo, Sherman and Krishna were afraid to complain to their boss about the racism at work. Rudo stated: "I am used to it for nine years. Now I don't care anymore". Krishna did not want to lose the medical benefit package her work offered as her husband had a heart condition and was unemployed. On one occasion, Krishna did speak up about the racism she experienced at work to improve conditions for other immigrant women but nothing was done. Exhausted, she quit her job. Enigma did not quit. She was fired from her job for not being a born again Christian. She took a photo of a small chapel she built in the backyard to demonstrate her Catholic faith and the hurt she experienced for not being allowed to maintain her faith at work. When Janavi complained about her racist experience: "My co-workers would be condescending... Ah! The immigrant girl is playing the colour card" (Janavi).

Referring to her photo of a brick wall, Rudo noted:

Sometimes when I am working I feel I hit a brick wall. There is no one to explain to how I feel with the racist behaviour of residents and some co-workers. When I complain to managers, they won't listen. Staff don't understand my culture. So I feel like giving up. I cannot see beyond the brick wall. I cry and I get really depressed. I feel fatigued. I think this is too much for my body and my mind (Rudo).

\section{Discussions and research implications}

The participants' experiences show that the social space they occupied (visible minority immigrant/refugee women) limited their access to high-skilled work in Canada's labour market, a labour market that undervalues human and social capital of non-white and non-European immigrants and refugees. These findings are consistent with other studies that provide evidence 
that visible minorities are disadvantaged and marginalised in Canada's labour market (Johnson, 2006; Perreault, 2008).

The participants in this research experienced systemic discrimination as well as direct discrimination. The women were racialised due to their immigrant status, ethnicity, language, culture and accent. When Rudo's client called her a "nigger" she experienced racialisation. Ruvashe's experiences of not being allowed to clean the woman who had a bowel movement suggests that she was dehumanised by her white client due to her black body. These results are consistent with other studies that demonstrate that immigrants are discriminated based on their race, culture and immigration status (Mahtani, 2004; Turrittin et al., 2002). These findings are worrisome. Discrimination is a determinant of immigrant health (Hyman, 2009).

It is noteworthy that most participants remained silent about the discrimination and racism at work. Very little is known about the link between employee silence in unfair work settings, health outcomes and organisational productivity. Although quiescent silence is driven by feelings of fear, acquiescent silence is motivated by feelings and beliefs of futility (Whiteside \& Barclay, 2013 , p. 252). It could be argued that in the initial years of employment, fear of the repercussions prevented Rudo, Krishna and Sherman from reporting the experiences of racialisation by their colleagues and clients to their supervisors. They did not want to lose their jobs. Over time, Rudo learnt that it was futile to complain to alleviate her suffering as her direct supervisor was also implicated in racist attacks. Her statement, "I am used to it for nine years. Now I don't care anymore," reflects a transition from employee quiescence to acquiescence, an adaptive response under the circumstances. Pinder and Harlos (2001) note "People in deep acquiescence have given up hope of improvement and become more or less oblivious to the importance of external events that may provide grounds for hope and a possibility for amelioration" (p. 349).

Acquiescent employees are less likely to take action to improve their situation and may ultimately leave the organisation.

More research is needed to understand the relationship between employee silence and health and organisational productivity. Aside from employee silence, the dark shadow of voicelessness or absence of voice pervades some of the study participants' lives. First, it is important to understand that silence and absence of voice are not the same thing. Paraphrasing Pinder and Harlos (2001), just as silence can communicate through thoughts, feelings and action, voices can be silent (p. 362-363). As explained earlier, when employees remain silent, it is generally due to the fear of the repercussions or passive resignation to the issue as in the case of Rudo. However, when employees wish to voice their thoughts or ideas, the motivation is generally to improve certain conditions or bring out a positive organisational change (Whiteside \& Barclay, 2013), as Krishna did.

Racism has negative consequences to the health of individuals (Hyman, 2009) and "regardless of the form of racial discrimination that takes place, the effects can be devastating to racialised groups" (Johnson, 2006, p. 2); It is therefore important to address racism and discrimination through anti-racist workshops, diversity training and training social workers in cultural competence and cultural sensitivity training. When immigrants encounter racism they can react with anger, hopelessness, helplessness, fear or paranoia, which then make them susceptible to various health problems (Clark, Anderson, Clark, \& Williams, 1999). Pursuit of social justice is one of the core values of social work (Canadian Association of Social Workers, 2005). Social workers can collaborate with other service providers and policy makers to educate the public on the effects of racism and discrimination. Further, globally, the schools of social work must take an active role in 
promoting dialogue about the settlement issues affecting immigrants and refugees through deliberate pedagogical strategies. Diversifying the curriculum through the inclusion of topics on immigration policies and other matters of social and economic justice from a micro and macro perspective will equip the new generation of social workers to provide culturally responsive services to this population. More research using innovative arts-based methods, such as photovoice, is needed to offer marginalised populations "an alternative form of voicephotographs as communication that allows for greater engagement" of participants in articulating their lived experiences (Chio \& Fandt, 2007, p. 487).

The photovoice methodology gave participants a voice. It seemed that through the process of photography, the women found the means to reveal their feelings and give voice to those experiences they found it difficult articulating in the English language. Language, especially when English is not participants' first language, has its limitation in expressing what is buried deep in the subconscious. There is power in the images that the eye of the camera is able to capture such as the photographs shared in this article. These photographs cross the boundaries and inhabit the participants' personal spaces that language can never touch.

Furthermore, photovoice allowed participants to voice their concerns from their perspectives and in multiple ways. For instance, participants took several photographs to highlight one particular problem or strength. As they reflected upon these images, participants appeared to develop a growing awareness of their unique experiences as immigrant visible minority women in Canada. "This awareness and cultivation of this awareness are the very building blocks and foundation for diversity itself: namely, the recognition and knowledge that difference comes from a somewhere and speaks to a something" (Chio \& Fandt, 2007, p. 490). Although voicing their concerns, participants seemed to enjoy the process of taking photographs. They were excited to show the author their masterpieces. There was a sense of pride in completing the project. Participants were also able to keep their photographs to share with family back home enabling a transnational family reflection to occur in some instances.

Using the photographs during the interviewing process helped to establish rapport between the researchers and the participants. It seemed that the photographs facilitated dialogue, encouraged laughter and tears, thus simplifying the process of establishing rapport with the participant and reducing researcher-researched distance. By modifying photovoice methodology, the author was able to bring the issues of power, inequality, voice and consciousness into the discourse of inquiry. For example, interviewing the women individually by using specific questions centred on Choice, Theme, Relationship, Issues and Message, the author was able to understand the meaning of the participant's photographs from their own standpoint. Understanding minority population's interpretation of what is 'helpful' and 'unhelpful' to them is integral in developing policies and programs for immigrant minority women.

Although there are many strengths of photovoice, there are some challenges in using this methodology. For example, this methodology can be very time-consuming. If the researchers are considering using photovoice, it would be important to clearly map out the different phases of photovoice and allocate a time line to each of the phases. The author found clearly that outlining the phases of photovoice and allocating a time line prior to begin the project assisted in keeping her on track with the research. As most of the interviews were done individually, it was easier to schedule appointments with the participants and stay faithful to the timeline. 
A further consideration is the cost associated with using photovoice methodology. This project used digital cameras and unless the researcher had project funding, this methodology could be financially prohibitive. Collaborating with community partners who are interested in community change and willing to assist with the cost of the project (for example, by donating cameras or providing assistance with printing photographs), can help to manage the cost of the project.

It is also important for researchers to keep in mind that some participants may have difficulty in utilising digital cameras and downloading the photographs onto the computer. Some participants may need extra help with these processes. It is also possible that this methodology may not be suitable for individuals from specific populations who are concerned for their own safety. For example, one refugee woman who was recruited for this research declined to take photographs. She was afraid that the photographs may cause political turmoil and pose safety issues to herself or to her family members. Researchers need to be cognisant of safety issues while working with refugee populations.

\section{Conclusions}

The results of the study show that as visible minorities, the participants experienced discrimination in the labour market and racism at work. In the absence of language, the women used the eye of the camera to uncover and communicate their lived experiences of discrimination and racism. Although this study provided useful information on discrimination and racism, more large-scale national level studies are needed to expand our understanding of how racism affects individuals and community health. In their efforts to create equitable social services, social work practitioners and academics must seek to understand how complex intersectionalities of gender and systemic factors (social, economic and political) inform visible minority women's experiences of racialisation. The use of photovoice as a method helped in gaining a holistic and contextual understanding of the participants' experiences of racism, moving this research beyond just listening to social action. Organising a community art exhibits to show the photos can shed light on the varied crevices of society's structures and enable women's voices to be heard by the policy makers. In doing so, photovoice transforms the participants from objects of research to actors, bringing women's voices to the forefront of community discourse, thus making their lived experiences of racialisation visible in society. Although every methodology has its limitations, by combining the power of photography with women's interviews "we might better understand the context that women confer to their lives and health conditions" (Wang, 1999, p. 186). The research findings are based on a diverse sample of visible minority women working in different occupations, although most of them were employed in low-paid occupations. It would be interesting for future research to explore the experiences of discrimination with women employed in high status jobs and those who are selfemployed.

\section{References}

Bilge, S. (2009). Smuggling intersectionality into the study of masculinity: Some methodological challenges. Paper presented at Feminist Research Methods: An International Conference, University of Stockholm, 4-9 February 2009. Retrieved from http://www.kvinfo. su.se/femmet09/papers/pdf/Bilge_revised.pdf

Canadian Association of Social Workers. (2005). Canadian social work code of ethics. Retrieved from http://www. casw-acts.ca/en/what-social-work/casw-code-ethics

Caragata, L. (1999). The privileged public: Who is permitted citizenship? Community Development Journal, 34(4), 271-286. doi:http:10.1093/cdj/34.4.270Caragata

Charmaz, K. (2006). Constructing grounded theory: A practical guide through qualitative analysis. London, United Kingdom: Sage Publications.

Chile, L. M. (2002). The imported underclass: Poverty and social exclusion of black African refugees in Aotearoa New Zealand. Asia Pacific Viewpoint, 43(3), 355-366.

Chio, V., \& Fandt, P. M. (2007). Photovoice in the classroom: Engagement, voice, and the 'Eye/l' of the camera. Journal of Management Education, 31(4), 484-504. doi:10.1177/1052562906288124 
Chui, T., \& Maheux, H. (2011). Visible minority women. (Catalogue no. 89-503-X). Retrieved from http://www. statcan.gc.ca/pub/89-503-x/2010001/article/11527-eng.pdf

Clark, R., Anderson, N., Clark, V., \& Williams, D. R. (1999). Racism as a stressor for African Americans: A biopsychosocial model. American Psychologist, 54(10), 805-816. doi:10.1037/0003-066X.54.10.805

Freire, P. (2005). Pedagogy of the oppressed. (M. B. Ramos Trans.). New York, NY: Seabury Press. (Original work published 1970)

Gordon, C. (2005). Knowledge of official languages among new immigrants: How important is it in the labour market? (Catalogue no. 89-624-XIE, Special Surveys Division). Retrieved from http://www.statcan.gc.ca/ pub/89-624-x/89-624-x2007000-eng.pdf

Hyman, I. (2009). Racism as a determinant of health. Policy brief. Retrieved from http://www.metropolis.net/pdfs/ racism_policy_brief_e.pdf

Johnson, T. (2006). The visible minority experience of marginalization in the Canadian labour force A proposal to the Ontario government to reintroduce employment equity legislation in Ontario. Discussion paper number 2006-06. 1-21. Retrieved from http://irc.queensu.ca/sites/ default/files/articles/the-visible-minority-experience-ofmarginalization-in-the-canadian-labour-force.pdf

Lal, S., Jarus, T., \& Suto, M. (2012). A scoping review of the photovoice method: Implications for occupational therapy research. Canadian Journal of Occupational Therapy, 79, 181-190. doi:10.2182/cjot.2012.79.3.8

Mahtani, M. (2004). Mapping race and gender in the academy: The experiences of women of colour faculty and graduate students in Britain, the U.S. and Canada. Journal of Geography in Higher Education, 28(1), 91-99. doi:10.1080/0309826042000198666

Padgett, D. (2008). Qualitative methods in social work research (2 $2^{\text {nd }}$ ed.). Thousand Oaks, CA: Sage Publications.

Perreault, S. (2008). Visible minorities and victimization. Canadian Centre for Justice Statistics Profile Series. (Catalogue no. 85F0033MIE). Retrieved from http://www. statcan.gc.ca/pub/85f0033m/2008015/5002072-eng.htm

Pinder, C., \& Harlos, K. (2001). Employee silence: Quiescence and acquiescence as responses to perceived injustice. Research in Personnel and Human Resources Management, 20, 331-369. doi:10.1016/ S0742-7301(01)20007-3

Reitz, J. (2001). Immigrant skill utilization in the Canadian labour market: Implications of human capital research. Journal of International Migration and Integration, 2(3) 347-378. doi:10.1007/s12134-001-1004-1

Rubin, A., \& Babbie, E. (2005). Research methods for social work ( $5^{\text {th }}$ ed.). Belmont, CA: Thomson Brooks/Cole.

Sethi, B. (2009). Exploring newcomer settlement and integration supports in Brantford, and Brant-HaldimandNorfolk Counties: Community-based participatory research (Master of Social Work Thesis, Wilfred Laurier University, Canada). Retrieved from http://scholars.wlu. ca/etd/921

Sethi, B. (2014). Intersectional exposures: Exploring the health effect of employment with KAAJAL immigrant/ refugee women in Grand Erie through photovoice (Comprehensive). Retrieved from http://scholars.wlu.ca/ cgi/viewcontent.cgi?article $=2737 \&$ context $=$ etd
Sethi, B., \& Williams, A. (2015). Employment experiences of visible minority immigrant women: A literature review. International Journal of Humanities and Social Science Research, 1, 134-143.

Singhal, A., \& Devi, K. (2003).Visual voices in participatory communication. Communicator: Journal of Indian Institute of Mass Communication, 37, 1-15.

Sutherland, C., \& Cheng, Y. (2009). Participatory-action research with (im)migrant women in two small Canadian cities: Using photovoice in Kingston and Peterborough, Ontario. Journal of Immigrant \& Refugee Studies, 7(3), 290-307. doi:10.1080/15562940903150089

Turrittin, J., Hagey, R., Guruge, S., Collins, E., \& Mitchell, M. (2002). The experiences of professional nurses who have migrated to Canada: Cosmopolitan citizenship or democratic racism? International Journal of Nursing Studies, 39(6), 655-667. doi:10.1016/S0020 7489(02)00003-2

Wang, C. (1999). Photovoice: A participatory action research strategy applied to women's health. Journal of Women's Health, 8(2), 185-192. doi:10.1089/jwh.1999.8.185

Wang, C., \& Burris, M. (1994). Empowerment through photo novella: Portraits of participation. Health Education \& Behaviour, 21(2), 171-186. doi:1177/109019819402100204

Wang, C., \& Redwood-Jones, Y. (2001). Photovoice ethics: Perspectives from flint photovoice. Health Education \& Behavior, 28(5), 560-572. doi:10.1177/109019810102800504

Whiteside, D., \& Barclay, L. (2013). Echoes of silence Employee silence as a mediator between overall justice and employee outcomes. Journal of Business Ethics, 116(2), 251-266. doi:10.1007/s10551-012-1467-3 